\title{
Correction to: Workflow Discovery Through Semantic Constraints: A Geovisualization Case Study
}

\author{
Vedran Kasalica and Anna-Lena Lamprecht
}

\begin{abstract}
Correction to:
Chapter "Workflow Discovery Through Semantic

Constraints: A Geovisualization Case Study"

in: S. Misra et al. (Eds.): Computational Science and Its

Applications - ICCSA 2019, LNCS 11621,

https://doi.org/10.1007/978-3-030-24302-9_34
\end{abstract}

The original version of the chapter starting on p. 473 unfortunately contained a mistake.

The presentation of Figures 4 and 5 was incorrect. The figures have been corrected. 